\title{
TTR
}

Traduction, terminologie, re?daction

\section{Objective Translational Error and the Cultural Norm of Translation}

\section{Brian Mossop}

Volume 2, numéro 2, 2e semestre 1989

L'erreur en traduction

URI : https://id.erudit.org/iderudit/037046ar

DOI : https://doi.org/10.7202/037046ar

Aller au sommaire du numéro

Éditeur(s)

Association canadienne de traductologie

ISSN

0835-8443 (imprimé)

1708-2188 (numérique)

Découvrir la revue

Citer cet article

Mossop, B. (1989). Objective Translational Error and the Cultural Norm of Translation. TTR, 2(2), 55-70. https://doi.org/10.7202/037046ar d'utilisation que vous pouvez consulter en ligne.

https://apropos.erudit.org/fr/usagers/politique-dutilisation/ 


\title{
Objective translational error and the cultural norm of translation
}

\author{
Brian Mossop
}

\section{Objective Identification of Error}

In l'Analyse du discours comme méthode de traduction, Jean Delisle gives a lengthy argument to justify his proposed French translation of the expression "a sense of loss » in a newspaper article which begins :

After the removal of her left breast because of cancer in 1970, Mrs. Joan Dawson, 54, of New York City spent the next three years battling depression and a sense of loss.
Une Newyorkaise de 54 ans, Mme Joan Dawson, subit en 1970 l'ablation du sein gauche atteint de cancer et passa les trois années suivantes à lutter contre la dépression et le traumatisme de la mutilation.

In my view, the underlined expression is an example of translational error. The problem with this specific rendering will be considered in section 3 below. In the first two sections, I will set out the basis for this judgment.

I want to suggest that the concept 'translational error' be defined in an objective and narrow manner. 'Objective' translation evaluation usually refers to an evaluation system that will let different evaluators arrive at similar conclusions. Here, however, 'objective' translational error means error which is identified without any reference to the goals of the translator vis-a-vis the readers of the translation, and without direct reference to the translator's interpretation of the text 'message'. 
What I propose is that the criteria for assessment be drawn from the translational norm of the target culture : a given rendering will be deemed to be a 'non-translation' if it fails to conform to the concept of translation predominant in the target culture. This has the virtue of providing an external standard for translation assessment-as opposed to a standard that is merely agreed upon among professional translators. Besides, it will surely be granted that approaching the concept of error without at least giving due consideration to the cultural norm would constitute a major theoretical oversight.

To use the cultural norm of translation as a criterion of correct translation goes contrary to prevailing trends in translation pedagogy and evaluation. Indeed, it is customary to ridicule the cultural norm of translation, in the form of disparaging remarks about 'transcoding' or 'formal equivalence'. But advocates of this customary approach succeed only in demolishing a parody of the translating norm. Having shot down easy targets in journalistic translation or the translation of tourist brochures-usually bits of nonsense which do not at all represent the norm-they proceed to replace the norm with one or another of the ways of translating prescribed by professional translators, translation teachers, and translation theorists. '

This substitute norm is typically defined in terms of the activity of the translator vis-a-vis the readers. The translator constructs a 'message' from the source text and then composes a new text reexpressing this message for readers within the target culture. A translation is erroneous if (in one view) it fails to sound like an original to the readers while having an equivalent functional impact on them, or (in another view) if it fails to have whatever impact the translating institution wants it to have.

In the substitute norm, it is the shaping work of the translator, as a cross-cultural text-interpreter and text-producer, which defines what translation is, and therefore how translation should be evaluated. For example, Larose (1988, p. 196) writes that «il existe des manières de traduire, donc des modes d'évaluation suivant l'intention de traduction (but du second énonciateur), facteur auquel doit être subordonné tout autre paramètre de traduction».

1. Here is a typical statement of a substitute norm : "The idea must be abandoned that translation is merely a matter of isolated words... translation begins with the text-in-situation as an integral part of the cultural background, whereby textanalysis proceeds from the macro-structure of the text to the micro-unit of the word, this being seen, not as an isolatable item, but in its relevance and function within the text. Furthermore, the text cannot be considered as a static specimen of language... but essentially as the verbalized expression of an author's intention as understood by the translator as reader, who then recreates this whole for another readership in another culture." (Snell-Hornby, 1988, p. 2). 
Readers may at this point think they are about to hear an argument for some form of literal translation. Not so. My proposal is that every text which is to be presented as a translation needs to undergo two separate evaluations: an evaluation in accordance with the cultural norm, and an evaluation as a piece of writing for a readership. It is in this sense that my proposal is for a narrow concept of translational error: only shortcomings detected during the first kind of evaluation will be called errors in translation.

The proposed approach is thus radically different from one which begins by looking at the macro-features of the translating situation (genre, readership, overall text function and so forth), and then assesses micro-level features (the translation of individual words, phrases and sentences) in terms of their contribution to achieving goals derived from the macro-level. My proposal is for unrelated macro-level and micro-level assessments. The micro-level would be assessed using criteria which do not take into account macro-level factors, because these are irrelevant to deciding whether a text is a good translation, as far as the cultural norm is concerned.

It is not hard to see that the results of the two assessments may well conflict: what the first assessment calls an error in translation may nevertheless be deemed a good piece of writing. But this is not a problem. The conflict reflects the reality of different cultural standards for writing and for translation (and perhaps also the fundamental contradiction at the heart of translation).

In practical evaluation work, it will simply be a matter of deciding when the writing criteria can override the translation criteria. 'Overriding' may be allowable, desirable, or even necessary in certain passages of a text, but if the number of overridings goes beyond a certain point, then the result, however valuable as a piece of writing, can no longer count as a translation (though it may be produced by someone who is called a translator). In this article, the writing criteria and the criteria for overriding will not be discussed.

I do want to emphasize that what is being considered here is translation evaluation, not translation procedure. Nothing that is said below should be taken to imply that translators should first translate literally and then decide when 'overriding' is allowable. By no means should translators proceed as if « the text [were] a linear sequence of units, and translation... a transcoding process involving the substitution of a sequence of equivalent units " (Snell-Hornby, 1988, p. 16), even if this is interpreted broadly to allow the substitution of equivalent cultural items. Rather, as translators work, they must of course identify the pattern of meaning that shapes the text and make inferences on the basis of the text as a whole and on the basis of their cultural, factual and situational knowledge, their knowledge of genres, their knowledge 
of the targetted readers, and so forth. What is being considered here is the final result, not the procedure that leads to it.

Before looking at the cultural norm of translation, I want to indicate its value as an objective means of identifying translational error, through a comparison with the alternatives :

(i) Equivalent effect : as Newmark (1988, p. 48) points out, the test of equivalent effect can be objectively applied only with texts that call on the reader to perform some action (like filling out an income tax form). Also, translators do not always aim for equivalent effect, and when they do not, it is still necessary to have a way of evaluating correspondence to the source text. ${ }^{2}$

(ii) Conformance to extratextual facts : again, this test can be applied only to certain kinds of text or certain passages within a text (e.g. a description of a piece of equipment).

(iii) Conformance to authorial intent: this test can be applied only when the author is available to state what his or her intent was, and even then there are three problems: the author may have forgotten ; texts can convey cultural meanings of which the author is not aware; and texts can accumulate meanings over time independent of what their authors intended.

(iv) Conformance to textual intent: the problem here is that not everyone believes in the objective existence of 'the intent of a text' ; there is a vast literature on text interpretation, ranging from ultra-subjectivism (every reading of a text is equally valid) to ultra-objectivism (there is only one valid reading).

By contrast, the cultural norm of translation has an undeniable objective existence (whose content, I hope to show, can be specified), and the test of conformance to the norm is applicable to every text (though the result is only a partial assessment of each text, since the norm does not cover every aspect of a translator's work).

2. In "Translating institutions : a missing factor in translation theory " (TTR, Vol. 1, no. 2), I mentioned the much discussed case of the Strachey translation of Freud, where terminology taken from everyday German (" das Ich ") is rendered by Latinate English (" the Ego *) - a case of deliberately changing meaning in order to make psychoanalysis sound like science. I suggested that the term 'mistranslation' not be applied to such cases but be restricted to changes in meaning that arise from carelessness or defective knowledge on the part of the translator. What I propose now is that the term 'non-translation' be applied to renderings like Ich = Ego. Both 'mistranslations' and 'non-translations' are 'translational errors'. 


\section{The cultural norm of translation}

The cultural norm I will be discussing is the one prevalent in my own English-speaking culture. I will not consider the degree of similarity to the norm in different or even related cultures. ${ }^{3}$

To identify the norm, what is really needed is an empirical study. This might involve a questionnaire administered to a group of unilingual speakers of the target language, as well as to a group of target-language speakers who can read the source language reasonably well. After a few questions designed to elicit a 'definition' of translation, bilingual respondents would be shown a variety of actual translations with their sources, and then asked questions about them (about individual passages and even words as well as about the text as a whole). The unilingual respondents would be shown translations at the 'literal' end of the scale, to determine the acceptability of various degrees of 'translationese'.

The main goal would be to determine what respondents would actually accept as translation (vs non-translation) and, secondarily, what they would accept as good translation (vs bad translation). A further goal might be to relate these assessments of actual texts to respondents' ideal definitions of translation.

Such a study - which I have not conducted - would doubtless produce some apparent self-contradictions within responses, as well as some responses that appear to contradict others. Nevertheless I believe that certain recurrent themes would emerge, and it is a worthwhile exercise to speculate about what these might be, if only as a way of bringing out questions that will need answering in any actual empirical study of the norm.

What I have done below is set out, on the basis of personal intuition and experience, what might be called a 'reasonable version' of the cultural norm of (written) translation. It will be seen that the specifications do not constitute anything like an algorithm, but that is because we are talking about a cultural norm for human translators, not a program for machine translation.

3. Antoine Berman (1988, p. 34) writes : « Il faut reconnaître qu'un Anglo-Saxon, un Allemand et un Français ne pensent pas... la 'traduction' de la même manière. Traduction, translation et Übersetzung ne 'se traduisent' pas mutuellement. " And specifically concerning French, he claims : "La langue française, elle, vost dans l'acte de traduire l'acclimatation adaptatrice de l'étranger. " This is certainly quite different from what I am claiming is the English concept - heavily oriented toward the notion of correspondences with the source-text wording. Berman writes that "la langue anglaise ne traduit pas, elle translate, c'est-à-dire fait circuler des «contenus " qui, en eux-mêmes, sont de nature translinguistique " (p. 33). This notion of translation as international circulation of supposedly culturally neutral, universal meanings may well be an aspect of the English norm. Close interviewing of the sort suggested in section 2 might clarify the matter. 
(i) Wherever the target language has the necessary structural devices, the translation has to by and large follow the source text small-unit-by-small-unit (word, phrase, clause, sentence). For each unit in the source, there must generally speaking be a formally similar unit in the translation, and corre-

sponding units must in most cases be in the same order.

Both the order principle and the structure-for-a-structure principle apply fairly rigidly to sentences, and with decreasing rigidity to smaller units. The order of sentences in the translation must follow that of the original, while the order of clauses, phrases and words is more flexible. Translating an abstract noun by an abstract noun ( «lors de son arrivée " by " at the time of his arrival " rather than "when he arrived") would not necessarily be required, whereas replacing an interrogative sentence by an interrogative sentence normally would be.

Thus a translation, according to the norm, is a text that is prepared from the wordings (lexical and syntactic choices) of the source text, and this manner of preparation is reflected in the result. Merely conveying the 'message' is not sufficient. Rendering « le rythme de reproduction des baleines est trop lent pour supporter une pêche intensive" as "since whales do not reproduce quickly enough, intensive harvesting is ruled out $»$ is non-translation. (These two sentences might appear in 'parallel texts'-texts on the same topic, written independently of each other or on the basis of discussion notes.)

The norm would reject gross violations of target-language grammar : it would thus very often require the order principle to be violated at the word level. However, some strangeness in syntax-as in vocabulary and phraseology-is allowed : the norm does not require translations to read like originals.

The norm would not be very tolerant of gross defects in intersentence cohesion (unidentifiable antecedents for pronouns, nonsensical connective particles, perhaps certain errors in the distribution of given and new information), though in other respects my impression is that the norm has little to say about structural equivalence above the sentence level.

(ii) In the treatment of the meaning of lexical units (words, but sometimes collocations or even larger sequences would be accepted as lexical units), the norm calls for a targetlanguage item, one of whose definitions in an ideal (i.e. complete) monolingual dictionary corresponds to (i.e. overlaps to a fair degree with) a definition of the sourcelanguage item.

These correspondences can be found, at least in principle, in a good bilingual dictionary. While such dictionaries are not created from 
corpuses of texts and their translations, they nevertheless do very often convey the experience of previous translators. They tell us that "pauvre " means "poor", and while strictly speaking this may only be information about the meaning potential of these words, it also conveys the experience of translators-that when Francophones use "pauvre " in an actual text, they very frequently mean what Anglophones mean when they use "poor". The reason for the frequent success of definition-based equivalences is simple: the dictionary definitions of corresponding items are based on real textual citations gathered by lexicographers (some of which are reproduced in good dictionaries to clarify the definitions).

The norm does not require, and indeed often rejects, literal translation in the sense of Newmark (1988, p. 69) : following targetlanguage grammar but rendering every lexical unit by its statistically most common out-of-context equivalent in the other language. This kind of substitution achieves near perfect success only with a few frozen expressions and with standardized technical terms, though as Newmark points out (p. 68), it does work surprisingly often in other cases as well.

Not only does the norm allow (and often require) expressions like "prendre connaissance de" and "exercice d'évacuation" to be treated as single units ( «peruse», « fire drill»), but also collocational information can be considered ( "pauvre» = «low", not "poor", in "minerai pauvre en métal»). Further, the topic of a text can be taken into account, just as it is in a good bilingual dictionary: nothing in the norm requires that French "nuage " be rendered as "cloud" in statistics texts, where one frequently finds reference to a «nuage de points" (a "cluster " or "scatter" of points around a line on a graph). I will not attempt to specify any further the degree and kinds of contextual reference allowed by the norm (but see the discussion of Delisle's translation in section 3 below, for a kind of extratextual appeal that is not included in 'context').

To sum up on this point, translation according to the norm is to a great extent a matter of 'dictionary equivalence', but the dictionary is conceived as a high-quality commercial lexicographical product (not a list of the 'signifiés' of linguistic theory), and it is assumed to be used by an intelligent human being, not a machine.

(iii) In the popular view of translation, the translated text is deemed to be 'by' the author of the source text. It is expected that the message is arriving from the point of view of the same 'voice' that is addressing the readers of the source text.

Whenever we read anything, we construct a picture of its source-the 'voice' that is addressing us (Mossop, 1987). This image 
may be that of an individual about whom we have independent knowledge, or it may simply be a category of person ('Quebec nuclear scientist') or an institution (a company describing warranty conditions on one of its products). The fact that translators have to construct a substitute 'voice', which is nevertheless supposed to be addressing the reader from the same viewpoint, may or may not be signalled by a certain degree of unidiomatic language ('translationese') - which the norm allows within limits.

This 'same voice' feature of the norm is formalized in the grammatical conventions of translation. In casual oral interpretation, "je me sens malade" can come out as "she says she isn't feeling well », where the voice addressing the listener is that of the interpreter reporting what has been said. But in written translation, the result will be "I feel ill», where "I» will be taken as the 'voice' of the source text if the text is presented as or understood to be a translation. ${ }^{4}$

An example of what this means is that the norm-following translator cannot replace sexist wordings with non-sexist wordings, because then the 'voice' addressing the reader will be dramatically changed.

This third feature of the norm in a way implies the other two : because the translation is taken as coming to the reader from the same 'addressing position' as the original, it follows that the wordings of the source text are not a mere key to unlocking the structure of a textual message, for they are the wordings that were selected at that 'position'. So small units of the source text have to be replaced with their conventional equivalents as much as possible. The norm sees translation as basically a translinguistic operation, rather than an operation that moves a textual message from one culture to another.

The concern of the norm with wordings is especially clear in the frequent use by journalists of expressions like « said the Prime Minister in French", following a direct-discourse quotation in English. Or consider the following extract from a letter to the Toronto Star by one of the Prime Minister's officials, concerning an interview the Prime Minister gave to a Paris newspaper :

The exact words [the PM] used, taken from the transcript of his interview with Le Figaro, were as follows : "Even if you would want it, ... " (23 Aug 89) [my emphasis]

4. Here is an example of overriding this aspect of the norm. I sometimes have occasion to translate letters from semi-literate members of the public complaining about their treatment by the unemployment insurance authorities. Following the translation norm could unfavourably impress officials who are prejudiced against the uneducated. On the other hand, 'improving' the writing could work against the complainant if the official who deals with the case has a prejudice in favour of the uneducated. My solution is to use indirect speech, making it clear that the voice addressing the official is the translator's : ( $M r$. X says he was treated rudely..." ). 


\section{Application of the Norm to Evaluation}

The 'reasonable version' of the cultural norm which I have set out allows for a considerable range of translation modes. It excludes all but occasional word-for-word renderings, and literal translations in Newmark's sense (defined above). But it includes other notions of literal translation, as well as Newmark's 'semantic' translation, and perhaps to some extent even his 'communicative' translation. ${ }^{5}$

However no definition can give a clear idea of what the norm includes and excludes. What is needed is to see, via detailed consideration of a number of actual translations, how the norm applies to each of the various aspects of translation work. There is no space for such lengthy consideration here, but among the matters to be considered are :

(i) What if anything does the norm have to say about making material that is explicit in the source text implicit in the translation, and vice versa? This begins with very simple cases, like replacing the second of two noun-phrases in French (eg "ces oiseaux...cette avifaune...") with a pronoun ( «the birds...they»). At the other end of the scale are cases of leaving the reader to make deductions based on subject-matter knowledge. The latter are non-translations, to be judged on the basis of writing criteria (e.g. whether the readers have the knowledge to recover concepts left implicit in the translation or, given the type of text, can be expected to go and acquire the knowledge). As for the replacement of French noun-phrases by pronouns, often this is either a stylistic requirement or it is essential to the 'mechanical readability' of the text. In the latter case, failure to replace may offend not just writing criteria but translation criteria as well: in certain cases, the norm might reject such failure in the same way it rejects gross grammatical error.

5. The third definition of literal transiation in Roberts (1988) reads : " the translator attempts to be faithful to the source text and original author by concentrating on the smaller units of the source text and by staying as close as possible to the style and primary meanings of the source text while ensuring the functional equivalence of the target text..." (p. 13). "Functional equivalence " here refers to equivalent effect on target readers. Compare this to Newmark's 'communicative' translation, which gives «the exact contextual meaning of the original in such a way that both content and language are readily acceptable and comprehensible to the readership " (1988, p. 47). Newmark's 'semantic' translation just gives « the exact contextual meaning of the original within the constraints of the TL grammatical structures $*(p .46)$. (See the discussion under point (ii) of section 2 for what I take to be included in 'contextual meaning'.) What all these definitions share is a strong emphasis on the wordings which the source-text author chose, while allowing, within that constraint, for varying degrees of attention to easing the task of the target-language reader. 
(ii) When translators also act as editors, 'correcting' the poor compositional habits of their source authors, is that nontranslation? I think so, but it is often necessary. The translator may sometimes have to use writing norms only, ignoring the translation norm.

(iii) Does the norm allow for correction when the wording contradicts what the translator knows extralinguistically to be the truth of the matter, or contradicts another passage in the text? No, but non-translation may be justifiable, and if it isn't, the norm allows for limited use of translator's notes.

(iv) What about cases where the translator 'fudges' because he or she does not know which of two or more possible meanings is intended? It may be that the norm does not contemplate the possibility of the translator being unable to understand the source text.

(v) Does the norm have anything to say about genre conventions? As far as page-layout matters are concerned, I think the answer is no. With respect to formulas like letter closings, "je vous prie d'agréer..." could be treated by the norm either as a single lexical item (with equivalent "yours truly" or whatever), or as a sequence of items for special-archaic or humorous-effect ( «I beg you to accept...»). With respect to the mode of addressing the reader, rendering a third-person declarative style in a French teacher's manual ( "L'étudiant rédigera deux textes...») by a second-person imperative style in English ( « Have the student write two papers...") would, I think, constitute non-translation, but writing criteria could override the norm.

(vi) What does the norm have to say about the translation of culture-specific metaphor: copy, replace or eliminate? What about place names and names of specific cultural entities: should one speak of the National Assembly in Québec or the provincial legislature in Quebec City? Tradition calls for "National Assembly in Quebec City ", which illustrates what may be a more general feature of the norm : cultural items should not be replaced with equivalents if the reader can understand the unadapted form without too much effort ( "Québec" often has to be replaced because of the risk of confusion with the name of the province), but the norm does not require immediate comprehensibility. 
Thus a reasonable version of the norm would, I think, allow for various treatments of 'cultural' expressions in the source text, from direct transcription of the source-language expression accompanied by an explanation, to substitution of an explanatory description, to replacement with an equivalent.

(vii) Translators often find that they cannot simultaneously render the informational content and the emotive connotation of an expression, and one or the other has to be sacrificed, with or without compensatory addition elsewhere. The norm probably allows for this, as seen in the popular notion "something got lost in the translation".

This list could go on, but the purpose here is merely to suggest rather than conclusively demonstrate the feasibility and value of a separate evaluation of translations in accordance with the cultural norm. I will just give one example of the application of the norm, using the passage from Jean Delisle's book reproduced at the outset of the article.

For the sake of argument, I will pretend that Delisle was writing about translation into English, so that I can avoid the question of whether the norm in Quebec or France is different. I use Delisle because I have not found a similar detailed argument for a case of French-to-English translation. The question of whether writing critera would justify overriding the translational norm in this particular case will not be considered, since it depends on the aim of the translator-a matter Delisle does not discuss.

Delisle begins (p. 105) by saying that «a sense of loss»

a un sens unique à ce contexte-ci même si l'expression existe en anglais et est couramment en usage dans les notices nécrologiques... Cette combinaison lexicale est dans ce discours anglais un emploi personnel et original.

Delisle appears to conclude that there is no connection with obituaries at all, for without any further argument, he completely abandons the usual meaning of the expression and its parts. He stops translating small units and substitutes a meaning he believes to be implicit, given his interpretation of the text as a whole:

Le co-texte ou contexte immédiat (...three years battling depression... Most women in the same situation turn to a psychiatrist) renvoie... à la partie de la médecine qui étudie et traite les troubles émotifs, les pathologies de la vie psychique. Perçu sous cet éclairage, «a sense of loss " évoque un choc émotionnel violent occasionné par la perte d'un sein. Ce choc émotionnel serait à l'origine de l'état dépressif... de Mme Dawson. (p. 109)

There are two problems here. First, Delisle is trying to make his translation of «sense of loss" give the cause of the depression. 
But nothing in the text suggests that Mrs. Dawson's sense of loss was a step on the road to ( "à l'origine de") her depression. The two expressions are simply joined by «and», and «depression» precedes «sense of loss». The English does not say or imply «sense of loss and (consequently) depression".

The other problem is that if «traumatisme » means, as Delisle says, "un choc émotionnel violent ", then it is far too strong for "sense of loss». A sense of loss is not a sharp, strong feeling, but a diffuse melancholy. If I were back-translating "le traumatisme de la mutilation », I would write " the shock of disfigurement » - something which has doubtless been experienced by other women who have had mastectomies, and might well be said in this sort of text, but was not said or implied in this text. Why assume that Mrs. Dawson was experiencing the same degree of trauma that would have led "most women" to consult a psychiatrist, especially since she went to a plastic surgeon instead?

The meaning of "sense of loss" can be obtained by a slight modification of the obituarial meaning. When we feel a sense of loss on the death of a loved one, our attention is focussing on the fact that in our conceptual/emotional picture of the world we inhabit, a space or position that was once occupied is now empty. The parallel to Mrs. Dawson's situation is clear : her breast occupied a certain position in her mental self-concept.

Delisle gives a list of translations suggested by his students. It includes «le vide qu'elle éprouvait» (p. 108), which seemed fully acceptable to a few Francophone translators I checked it with. The relevant entries for "vide» in the Lexis and Robert dictionaries are :

sentiment de privation (la mort du père a fait un grand vide) $(L)$; ce qui est ressenti comme un manque (son départ fait un grand vide) $(R)$

Alternatively, "sentiment de privation" itself could be used, or else "vide émotif", if it is thought desirable to avoid any suggestion of a physical hole rather than a mental one. These all correspond in a clear way to the relevant meanings of "sense " and "loss" as given in Webster's :

sense - an awareness or feeling of a particular nature resulting from a particular stimulus (a sudden sense of warmth on entering the house); a self-conscious motivating awareness or conviction (tried to control his sense of injury)

loss - the harm or privation resulting from losing or being separated from something or someone (bore up bravely under the loss of both parents)

Delisle's translation offends the norm because it renders concepts which the translator believes (rightly or wrongly) are implicit in the text, and ignores the source author's word choices. 


\section{Where is the boundary between translation and non-translation ?}

It is worth quoting at length Delisle's views on the limits of translation :

Il y a une limite que le traducteur doit s'interdire de franchir. Dans les milieux canadiens de la traduction, une nouvelle tendance se dessine... Conscients du danger (réel) d'atrophie qui menace une langue s'exprimant plus souvent à travers des traductions que dans un emploi original, comme c'est le cas du français au Canada, des traducteurs et réviseurs... se font les adeptes d'une forme de « réécriture élégante »... Cette pratique n'ouvre-t-elle pas la voie à une version moderne des « belles infidèles » ? Par nature, la traduction suit le cheminement général du texte original et, par conséquent, elle peut difficilement prendre la forme d'une « variation sur un thème connu" ou d'une "imitation". Ces exercices de rédaction sont en fait des adaptations libres qui n'osent dire leur nom. (p. 118)

Here is Delisle's conception of an 'adaptation' of the passage we have been considering :

Non, ce n'était plus tenable. Mme Dagenais, Montréalaise de 54 ans, ne pouvait plus supporter l'état dépressif qui l'accablait depuis trois ans. L'ablation d'un sein l'avait profondément affectée. Son moral était au plus bas. (p. 118)

But this is too clear a case of non-translation. While there will inevitably be a gray area between translation and non-translation, Delisle does not show how his concept of non-translation applies in a not-so-clear case.

He does, however, go a bit further than the rather vague «la traduction suit le cheminement général du texte original ", cited above. In discussing what he calls the «analyse justificative » of a proposed translation, Delisle says that the point of the analysis is to determine "dans quelle mesure la formulation retenue est conforme au sens du passage original, ou, plus exactement, à son interprétation personnelle du vouloir-dire de l'auteur du texte» (p. 83).

The problem as I see it with Delisle's approach is precisely that he wants to justify translations solely by reference to the translator's interpretation of the authorial or textual intent, with no reference to the wordings of the source text. This leaves open far too wide a scope for the subjectivity of both the translator and the translation evaluator.

In his discussion of justificatory analysis, Delisle gives the following warning : «Une interprétation objectivement fausse peut donner lieu à une justification subjectivement logique. "It is not clear to me how Delisle decides that an interpretation is «objectivement fausse ", but he does explain "subjectivement logique": one can become very attached to one's own interpretation, "surtout lorsqu'il est impossible de s'appuyer sur des évidences linguistiques et factuelles" (p. 83). The point I have been trying to make here is that Delisle does not 
give enough weight to "les évidences linguistiques». His approach takes the translator's and the evaluator's attention away too quickly from the actual words the author has chosen and focusses it on the overall context, which then plays a preponderant role in determining what meaning is assigned to any given passage.

\section{Concluding Remarks}

In much contemporary writing about translation, there is often a confusion between observations and discoveries about translation on the one hand, and on the other hand prescriptions about how people-translators, employers, teachers, clients, the public-ought to view (and hence evaluate) translation.

The prescriptive aspect is tied up with how translators hope to be treated, namely, in a manner as far removed as possible from what would be dictated by the view that translation is basically word replacement and can therefore be automated. In the past two decades, translators have sought to define themselves-against the cultural norm-as professional intercultural communications experts, and thus to position themselves favourably for an important role in the "new information order' which is supposedly coming into being.

It is perfectly legitimate to claim that we have discovered that translation cannot be modelled by the word replacement procedure of early (or even more recent) machine-translation experiments. The word replacement model of MT (and of stereotyped versions of the cultural norm) is certainly too simple to describe translation as it is conceived by either the reader-oriented text-theorists or the more source-oriented cultural norm.

It may also be the case, as some practitioners and teachers of oral interpretation have claimed, that word replacement can play only a minor role in the conditions under which spoken translation is performed. There is simply no time to pay close attention to wordings, and immediate comprehension by the listeners is paramount since, unlike readers, they cannot 'listen slowly' or 'relisten'. ${ }^{6}$

6. Danica Seleskovitch, a leading proponent of the view that translation is the rendering of the translator's interpretation of discoursal meaning, not of the wordings of the text, says that in writing, unlike in spoken discourse, " le discours devient accessible non plus seulement dans sa partie sens mais aussi dans la langue dont il est fait... La formulation linguistique subsiste ainsi de plein droit... Le traducteur ne peut pas pour autant se dispenser de l'interpréter et de lui donner le sens qui lui paraît le plus probant : mais on comprendrait mal qu'il ne respecte pas cette vie linguistique indépendante et qu'il ne fasse pas le maximum d'effort pour rapprocher sa traduction des formes linguistiques de l'original " (Seleskovitch, 1976, p. 79). This prompts the questions " how much of an effort?" and "what is the required degree of rapprochement? " A few 
But it does not follow from any of this that written translation is, by nature, wholly different from what the word replacement model suggests. No Chinese wall can properly be erected between translating 'words' on the one hand and translating 'ideas' or translating 'languagein-situation' on the other. The notion that translation is a rendering not of 'langue' but of 'parole' is too simplistic.

Professional translators may want translation to be conceived as utterly different from word replacement, and they may be trying to change the cultural norm of translation, but unless such a change actually comes about and translation is re-conceived by the public as just another kind of writing-for-readers, the existing cultural norm stands, as an objective limit and control on what counts as translation. Its objectivity is twofold. First, like any norm, it has an objective social existence. Second, the current norm provides control via its reference to the two linguistic systems, which have a social existence independent of the source author, the reader of the translation, and most importantly, the translator.

Secretary of State Translation Bureau, and York University School of Translation, Toronto

lines earlier, Seleskovitch describes the work of rapprochement as « un souci supplémentaire, celui de respecter le signifié original et de conserver dans une certaine mesure [dans quelle mesure ? - BM] les formes originales $»$. It all sounds a bit like icing on the cake - important for appearances but not really essential. The writings of Seleskovitch and her followers often point out that writing differs from speech in that linguistic form plays a greater role, but they then deny that the difference is really significant. In their view, interpretation and (written) translation involve the same basic process of understanding - best seen in the spoken mode - and the result should be evaluated in basically the same way. "Sur l'essentiel, l'interprétation et la traduction ne differrent pas... toutes deux se libèrent de l'emprise linguistique de l'original. » (p. 79) 


\section{References}

BERMAN, Antoine (1988). "De la translation à la traduction». TTR, (Vol. 1 , no. 1), pp. 23-40.

DELISLE, Jean (1984 [1980]). L'Analyse du discours comme méthode de traduction, Ottawa, Éditions de l'Université d'Ottawa.

LAROSE, Robert (1988). Théories contemporaines de la traduction, Québec, Presses de l'Université du Québec.

MOSSOP, Brian (1987). "Who is Addressing Us When We Read a Translation?". TextConText (Vol. 2, no. 1), pp. 1-22.

NEWMARK, Peter (1988). A Textbook of Translation, London, Prentice Hall.

ROBERTS, Roda (1988). «Literal Translation : Different Concepts Underlying the Term ». Terminology Update (Vol. 21, no. 1), pp. 11-13.

SELESKOVITCH, Danica (1976). "De l'expérience aux concepts ", Études de Linguistique Appliquée, no. 24, pp. 64-91.

SNELL-HORNBY, Mary (1988). Translation Studies, Amsterdam, John Benjamins. 